Chapter 15

\title{
Simulation of Biofuels Combustion in Diesel Engines
}

\author{
Andrey Marchenko, Alexandr Osetrov, \\ Oleg Linkov and Dmitry Samoilenko \\ Additional information is available at the end of the chapter \\ http://dx.doi.org/10.5772/52333
}

\section{Introduction}

In the study of the working process, the development of new engine construction or modernization of an existing one is necessary to use simulation with mathematical models. Modeling of the processes inside the cylinder allows in a first approximation to evaluate engine performance, choose the rational value of adjustment or constructive parameter, to reduce material, labor and time required to conduct experimental research.

One of the most difficult process for simulation is the combustion process in diesel engines. This process is determined and accompanied by a number of other processes and phenomena. There is intense interaction between the motion of the fuel jets and air flow in the cylinder, heat transfer between the combustion chamber zones and walls, volume evaporation from the surface of liquid droplets. All this leads to the formation of the active nucleus of the fuel oxidation and its ignition, volumetric and then the diffusion combustion.

Currently, there are a number of hypotheses about the behavior of each of these processes and their interaction. For each hypothesis proposed mathematical description of a different degree of accuracy.

The most complex model implemented technology of Computational Fluid Dynamic (CFD) three-dimensional simulation of gas flow and the injected fuel in the cylinders and manifolds of internal combustion engines [1-5]. The most popular programs are: KIVA (Los Alamos National Laboratory, Los Alamos, New Mexico); STAR-CD (CD-adapco, headquarter Melville, New York, USA); FIRE (AVL, headquarter in Gratz, Austria); VECTIS (Ricardo, headquarter Shoreham-by-Sea, England, United Kingdom).

For example, the software package AVL FIRE Engine includes over 20 different models of formation and spread of the jet, its decay, crushing drops, collisions between them, the 
evaporation of fuel and its interaction with the wall of the combustion chamber [6]. The formation of liquid films, their distribution and evaporation, the interaction with the walls and the liquid fuel torches are also simulated. Several models describe the processes of ignition, combustion and the formation of harmful substances, taking into account detailed chemical kinetics of reacting systems.

A significant technical challenge of CFD models is the complexity of calculations and the need for powerful computers. Data preparation only for one simulation with highly skilled personal could takes a few days. Calculation time for one variant of the engine - a few hours and sometimes days. Implementation of these programs for optimization calculations is problematic because optimization process has to count thousands of design options.

Thermodynamic and phenomenological models that use the 0 - or 1-dimensional representations, require less time and resources. The most popular programs were GT-Power (Gamma Technologies, Inc, headquarter Westmont, Illinois, USA), BOOST (AVL,Gratz, Austria), WAVE (Ricardo, Shoreham-by-Sea, England, United Kingdom), DIESEL RK (Moscow State Technical University named after Bauman, Moscow, Russian Federation). These software products usually include a one-dimensional model of gas exchange. To calculate the mixing and combustion in a diesel engine used empirical or semi-empirical models [7-11].

The most sophisticated models of combustion used in thermodynamic models are models of H. Hiroyasu [9], as well as Razleytsev N.F. and Kuleshov A.S. models[7, 8]. In these models, the propagation of fuel jet is described by the criterial equations obtained on the basis of experimental data. It has been assumed in this modelsthat the main influence on the rate of heat generation rate has drops evaporation rate and the speed of the air penetrated in the combustion zone. Also, the effects of air swirl on the development of fuel sprays is considered. In models of mixing, combustion and evaporation using an average diameter of the droplet on the Sauter. The fuel jet is considered as a set of zones, each of which has a characteristic temperature, the volume, fuel-to-air ratio.

These models allow us to investigate the influence on the combustion of compression, timing and duration of the injection, hole diameter and the number of sprays in the fuel injector, characteristics of fuel injection, combustion chamber shape, correlate the direction of fuel jets with combustion chamber and swirl intensity, take into account the interaction of jet fuel with the walls and to each other and finally allow you to perform multi-factor multi-criteria optimization.

However, the use of this class of models requires detailed design information of the simulated engine, setting up empirical relations and coefficients to make a relatively labor-intensive verification.

Widespread empirical or semi-empirical models of combustion, which describe the geometric shape of the heat generation curve [10-15] (second group) are also presented. Such models are easy to describe and versatility of use. For example, in a model of prof. VibeI.I. [10], the rate of combustion and the proportion of burnt fuel are described by semi-empirical dependencies: 


$$
\begin{gathered}
\frac{d x}{d \varphi}=-C \frac{m+1}{\varphi_{z}} \varphi^{m} \exp \left(C \varphi^{-m+1}\right) \\
x=1-\exp \left(C \bar{\varphi}^{-m+1}\right)
\end{gathered}
$$

where $\bar{\varphi}=\left.\varphi\right|_{\varphi_{z}{ }^{\prime}} \varphi, \varphi_{z}$ - respectively, relative duration of combustion, the current duration of combustion from the start of combustion and combustion duration shown in angles of rotation of the crankshaft;

$C$ - constant (for example, at the end of the combustion when $x=x_{Z}=0.999, C=\ln (1-0,999)=$ $-6,908)$;

$m$-index of combustion character.

Feature of empirical models is that all input values of the calculation formulas are constant values and are given by experimental data or chosen from the recommended by investigators ranges. For example, in first approximation, prof. Vibe I.I. recommends $0 \leq m \leq 0,7$ for diesel engines, and in the work of scientists from Bauman Moscow state University(Moscow, Russian Federation) values of $m$ range from -0.3 to 0.7 .

Use of this class of models suitable for describing the combustion in a specific engine running on one mode of his work. When changing a constructive parameter and adjusting the engine or the conditions of his work empirical models stop producing an accurate result.

The drawback of empirical models of combustion is the complexity of their use in calculations of the harmful substances formation in diesel engines, in particular nitrogen oxides. NO output in accordance with the thermal theory of ZeldovichU.B. [16] is extremely sensitive to the magnitude of the temperature in the cylinder. Therefore, in these calculations, it is important to accurately determine the temperature and, consequently, the heat generation curve. This curve, calculated by the empirical models as a rule have one peak that does not comply with the combustion process in diesel engines for most modes of operation. Accordingly, the accuracy of the calculation output of harmful substances by using models of this class is relatively low.

Most of the problems that arise in the practice of design and research of various diesel engines can be solved using "intermediate" type models [11, 18-20] (third group). These models combine the advantages of computational methods from first and second groups.

A number of models describes the combustion process by using Vibe I.I. relationships (1) and (2) $[19,20]$, but unlike empirical models the indices of combustion duration $\varphi_{z}$ and combustion character $m$ are functions of design parameters and operation modes.

The data obtained by processing the experimental indicator diagrams, confirm the correctness of this approach (Fig. 1) 


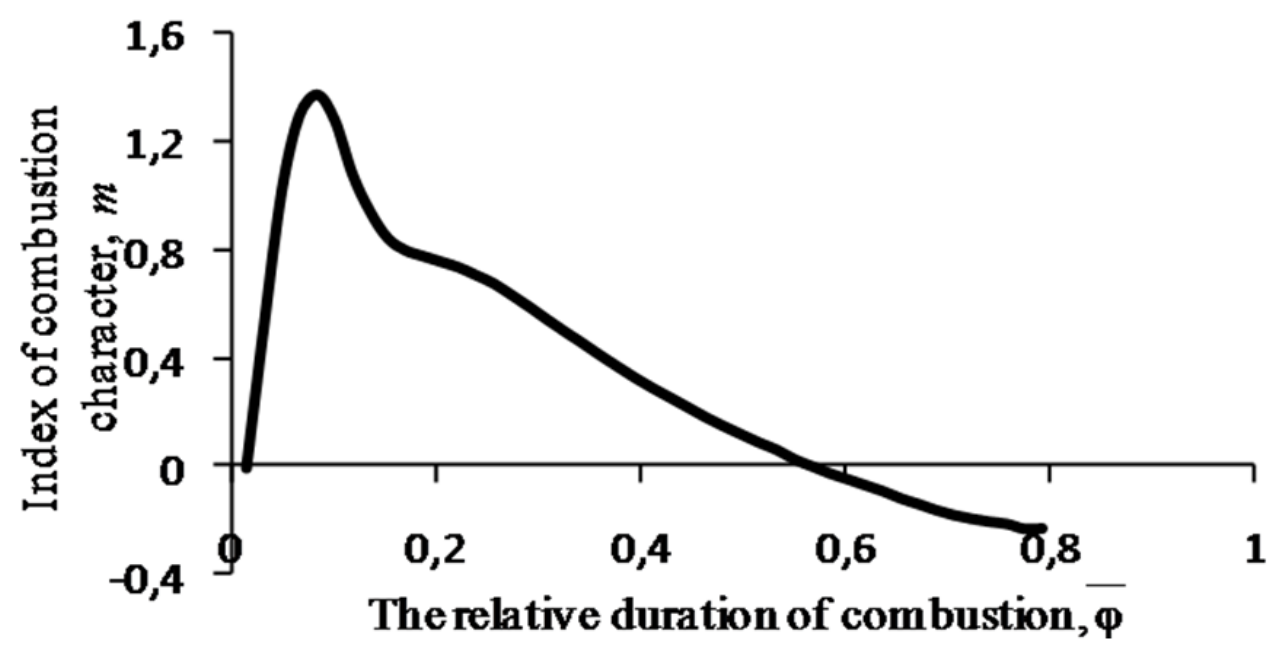

Figure 1. The change in the index of combustion character $m$ during operation cycle in the 4 stroke autotractor diesel engine with turbocharger (SMD-23)

According to the variable nature of the index of combustion characterm for the differentiation of equation (2) the next dependence was obtained which is different from equation (1): $\frac{d x}{d \varphi}=-C \exp \left(C \bar{\varphi}^{m+1}\right) \frac{1}{\varphi_{z}}\left[(m+1) \bar{\varphi}^{m}+\bar{\varphi}^{m+1} \ln \bar{\varphi} \frac{d m}{d \bar{\varphi}}\right]$

Filipkovsky A. I.proposed to determine the index of combustion characterm and the duration of the combustion $\varphi_{z}$ in Vibe I.I. dependencies (1) and (2) as a function of the parameters of the evaporation, diffusion and chemical kinetics of reaction [19]. The model takes into account the main factors that determine the combustion process:

- design features of the combustion chamber (chamber shape, the diameter of the cylinder and the neck chamber, swirl ratio);

- characteristics of the fuel injection and atomization (diameter and the effective cross section of nozzle holes, duration, and mean pressure of injection, amount the fuel during operation cycle, the physical characteristics of the fuel);

- thermo-and gas-dynamic parameters of the charge in cylinder (pressure and density of charge at the end of a conditional extended to top dead centre (TDC) compression, the tangential velocity of the charge in the combustion chamber);

- mode parameters of the engine (speed, excess air ratio).

The model assumed that the development of chain reactions begins with the start of fuel injection into the diesel cylinder, rather than the beginning of combustion, as in the model of prof. VibeI. I. The curve of heat generation rate, calculated by the model, has one peak. 
Calculations of heat curves by the model of Filipkovsky A.I. for medium-speed four-stroke diesel engines with turbocharging, $26 \mathrm{~cm}$ bore and stroke $34 \mathrm{cmand}$ four-stroke diesel engines with turbocharging, $32 \mathrm{~cm}$ bore and stroke $32 \mathrm{~cm}$ with volume mixing processes have shown good agreement with experimental data. However, practical application of this model for highspeed automotive diesel with a volume-film-mixing processes did not produce positive results. The discrepancy between the calculated and experimental data is greatest in the partial modes, where the curve has a two-peak heat generation rate in nature (Fig. 2). Finally, this method gives a significant error in the calculations for biofuels because of significant differences in the physicochemical properties of diesel fuels and biofuels.

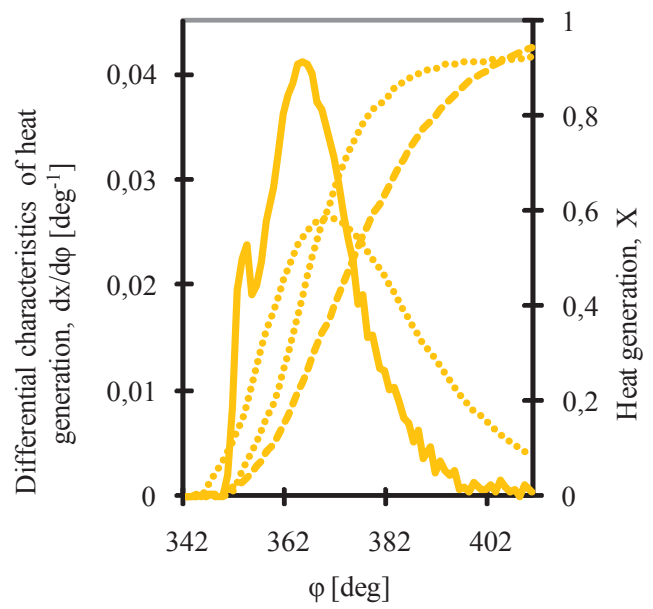

Figure 2. Comparison of experimental and calculated heat generation characteristics of the ethyl esters of rapeseed oil - Experimental data

Despite these problems, the Filipkovsky A.I. model, in our opinion, has the potential for further improvement. Obviously, it is necessary to adapt this model to integrate features of mediumspeed diesel engines, physicochemical properties of biofuels, as well as operation modes of small and medium loads, where the heat generation rate has two-peak character.

Significant influence on the combustion process have physical and chemical properties of fuel. In present study, the features of the processes in the engine cylinder associated with the use of bio-fuels of plant-based origin, in particular mixtures of rapeseed oil (RO) with diesel fuel (DF) and the ethyl ester of rapeseed oil (EERO). In conducted by authors experimental studies have shown that the presence of oxygen in the molecule of biofuels will intensify the process of diffusion combustion, which should be considered when developing a mathematical model.

This chapter describes the results of experimental studies of biofuels in diesel engines, the mathematical model of combustion in the diesel enginecylinder and the results of verification. 


\section{Experimental studies of biofuels in diesel engines}

Experimental studies are needed to obtain basic data for modeling, getting a number of empirical coefficients in the model equations and refinement of physical laws, comparison of experimental and calculated data.

\subsection{Investigation of physicochemical properties of biofuels}

Physicochemical properties of the investigated biofuels are presented in Table 1.

Analysis of the data in Table. 1 shows that the properties of plant-based fuels are significantly different from the properties of diesel fuel: PM and EEROafter comparison with DFhave respectively 14 and $13.5 \%$ less low heat values, for 10 and $8.1 \%$ higher density, for 14.1 and $21.9 \%$ higher surface tension, and for 22.8 and 8.5 times higher viscosity. For the combustion of $1 \mathrm{~kg}$ of RO and EERO required respectively 12.7 and $12.6 \%$ less air, which is associated with the presence of oxygen in the structures of their molecules.

It should be noted that the trial set of EERO contained unreacted raped oil, so the physical and chemical properties of ethyl differ are different from those given in the technical literature [21].

\begin{tabular}{|c|c|c|c|c|c|c|}
\hline \multirow[t]{2}{*}{ Property } & \multirow{2}{*}{$\begin{array}{l}\text { Diesel fuel } \\
\text { (DF) }\end{array}$} & \multirow{2}{*}{$\begin{array}{l}\text { Rape oil } \\
\text { (RO) }\end{array}$} & \multirow{2}{*}{$\begin{array}{c}\text { Ethyl ester of } \\
\text { rapeseed oil (EERO) }\end{array}$} & \multicolumn{3}{|c|}{ Mixtures } \\
\hline & & & & $\begin{array}{c}\text { DF: RO } \\
(3: 1)\end{array}$ & $\begin{array}{l}\text { DF: RO } \\
(1: 1)\end{array}$ & $\begin{array}{l}\text { DF: RO } \\
(1: 3)\end{array}$ \\
\hline \multicolumn{7}{|l|}{ Elemental composition, \%: } \\
\hline carbon (C) & 87 & 77,9 & 77,6 & 84,5 & 82 & 79,8 \\
\hline hydrogen $(\mathrm{H})$ & 12,6 & 11,9 & 12 & 12,3 & 12 & 11,8 \\
\hline oxygen (O) & 0,4 & 10,2 & 10,4 & 3,2 & 5,9 & 8,5 \\
\hline sulfur (S) & 0,04 & 0 & 0 & 0,03 & 0,02 & 0,01 \\
\hline $\begin{array}{l}\text { The amount of air for combustion per mass } \\
\text { unit of fuel Lo, } \mathrm{kg} / \mathrm{kg}\end{array}$ & 14,4 & 12,7 & 12,7 & 13,9 & 13,5 & 12,9 \\
\hline High heat value Qv, MJ / kg & 44,95 & 39,3 & 39,2 & 43,4 & 42,0 & 40,6 \\
\hline Low heat value of Qn, MJ / kg & 42,2 & 36,8 & 36,9 & 40,7 & 39,3 & 38,0 \\
\hline The density $\rho, \mathrm{g} / \mathrm{m} 3\left(20^{\circ} \mathrm{C}\right)$ & 825 & 915 & 895 & 849 & 872 & 894 \\
\hline The kinematic viscosity v, $\mathrm{mm} 3 / \mathrm{s}\left(20^{\circ} \mathrm{C}\right)$ & 3,8 & 87 & 32,48 & 26,3 & 47,6 & 67,8 \\
\hline The surface tension $\sigma^{*} 103 \mathrm{~N} / \mathrm{m}\left(20^{\circ} \mathrm{C}\right)$ & 28,9 & 33,3 & 36 & 30,1 & 31,2 & 32,3 \\
\hline
\end{tabular}

Table 1. Physicochemical properties of biofuels.

The difference between the physical and chemical properties of biofuels on the properties of diesel fuel is the cause of changes in diesel working process and performance, which should be considered when simulating processes inside the cylinder. 


\subsection{Studies of dispersion atomized biofuels}

To clarify the empirical and criterial relationships that characterize the quality of atomization of biofuels, an experimental study was made of atomizationdispersion.

Single injections were made on glass plates coated with a layer of soot and kerosene and on a top side covered with a layer of magnesium oxide (which has a bright white color) for clarity of prints fuel droplets.

The studies were conducted on the following frequencies of high pressure fuel pump camshaft rotation: 900,700 and $770 \mathrm{rpm}$. Fuel rack setting was made for maximum fuel delivery.

Micrographswere obtained in the experimental study of dispersion of the atomization of various fuels and shown on Fig. 3.

Photomicrographs are processed according to the procedure [22]. The relative fuel atomization characteristics were obtained as the results (Figures 4-7): Differential (R0 - quantitative; R2 surface; R3 - volume) and integral (S0 - quantitative; S2 - surface; S3 - volume).

The data obtained allowed to estimate the average diameter of fuel droplets of different composition.

The most commonly used parameter for calculating the evaporation of fuel is the average volume-surface droplet diameter (Sauter diameter):

$$
d_{32}=E_{32} d_{c} M^{0.0733} /(\rho W e)^{0.266}
$$

where $E_{32}$ is a constant factor depending on the design of the nozzle and the method of averaging the droplet size;

$d_{c}$-diameter of atomized holes;

$M$-criterion, which characterizes the ratio of surface tension and viscosity;

$W_{e}$ - Weber criterion;

$\rho$ - air density to fuel ratrio

Calculations of Sauter diameter of droplets for a four-stroke auto-tractor turbocharged diesel engine, which has a cylinder diameter $120 \mathrm{~mm}$ and $140 \mathrm{~mm}$ stroke running on standard diesel fuel using the standard fuel system show that the value of $d_{32}$ on nominal power mode ranges from 26 to 29 microns. Greater droplet diameter values obtained in experimental studies (Fig. $4)$, due to the fact that the injection was made into the environment under atmospheric conditions. It is obvious that in a running diesel engine a high temperature of the charge in the cylinder causes a greater atomization and evaporation of fuel droplets.

Therefore, when refinement dependencies (3) for the case of biofuels, relative (not absolute) values of $d_{32}$ (Table 2) was used. Analysis of the data in Table. 2 shows that the dependence (3) with appreciable error describes the variation of $d_{32}$ for plant-based fuels. Authors have pro- 
posed an empirical correction for the dependence (3), depending on the viscosity of the fuel and allows to do more accurate calculation of the average volume-surface diameter of drops:

$$
k_{f}(v)=-0,00010939 \cdot v^{2}+0,0052066 \cdot v+0,98179447 .
$$

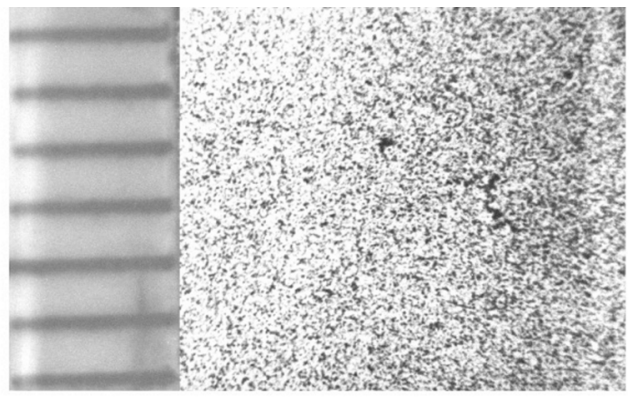

(a)

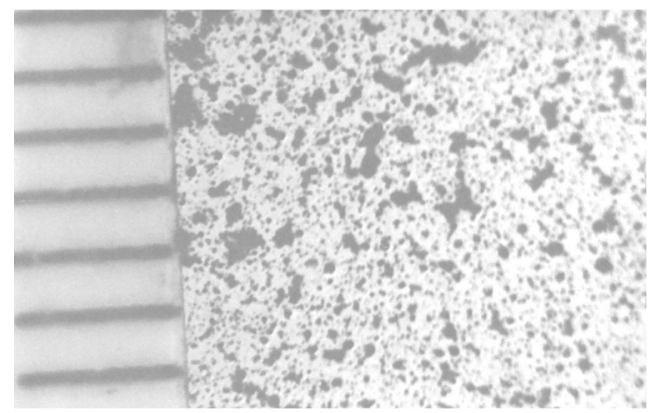

(c)

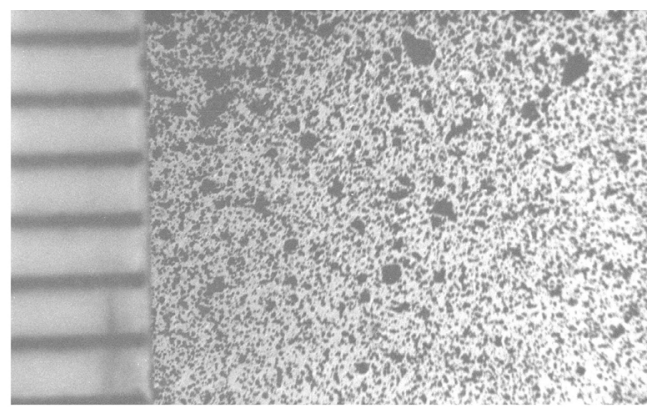

(b)

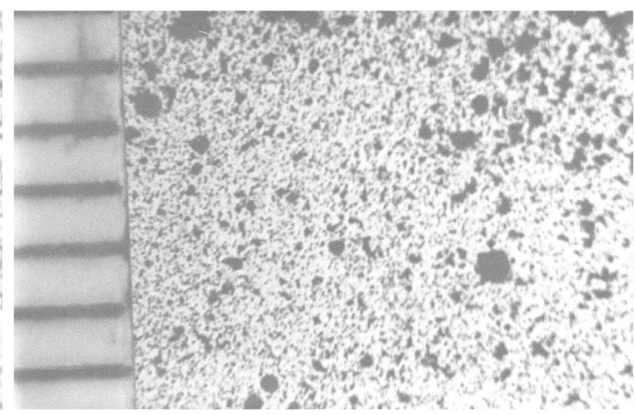

(d)

Figure 3. Micrograph of atomized fuel droplets ( $n=900 \mathrm{rpm}$ ): a standard diesel fuel (a) a mixture of diesel fuel and rapeseed oil in the ratio 1:1 (b); pure rapeseed oil (c); ethyl ester of rapeseed oil (d)

\begin{tabular}{lcccc}
\hline & $\begin{array}{c}\text { Diesel Fuel } \\
\text { (DF) }\end{array}$ & $\begin{array}{c}\text { Mixture } \\
\text { DF: } \mathbf{R O}(\mathbf{1 : 1 )}\end{array}$ & $\begin{array}{c}\text { Rape Oil } \\
\text { (RO) }\end{array}$ & $\begin{array}{c}\text { Ethyl ester of rapeseed } \\
\text { oil(EERO) }\end{array}$ \\
\hline $\bar{d}_{32}$ (experiment) & 1,00 & 1,509 & 2,000 & 1,877 \\
\hline $\bar{d}_{32}$ (calculated by the formula (3)) & 1,00 & 1,537 & 3,176 & 1,488 \\
\hline $\bar{d}_{32}$ (adjusted value) & 1,00 & 1,509 & 1,927 & 1,541 \\
\hline
\end{tabular}

Table 2. The relative diameters of the droplets of different fuels 


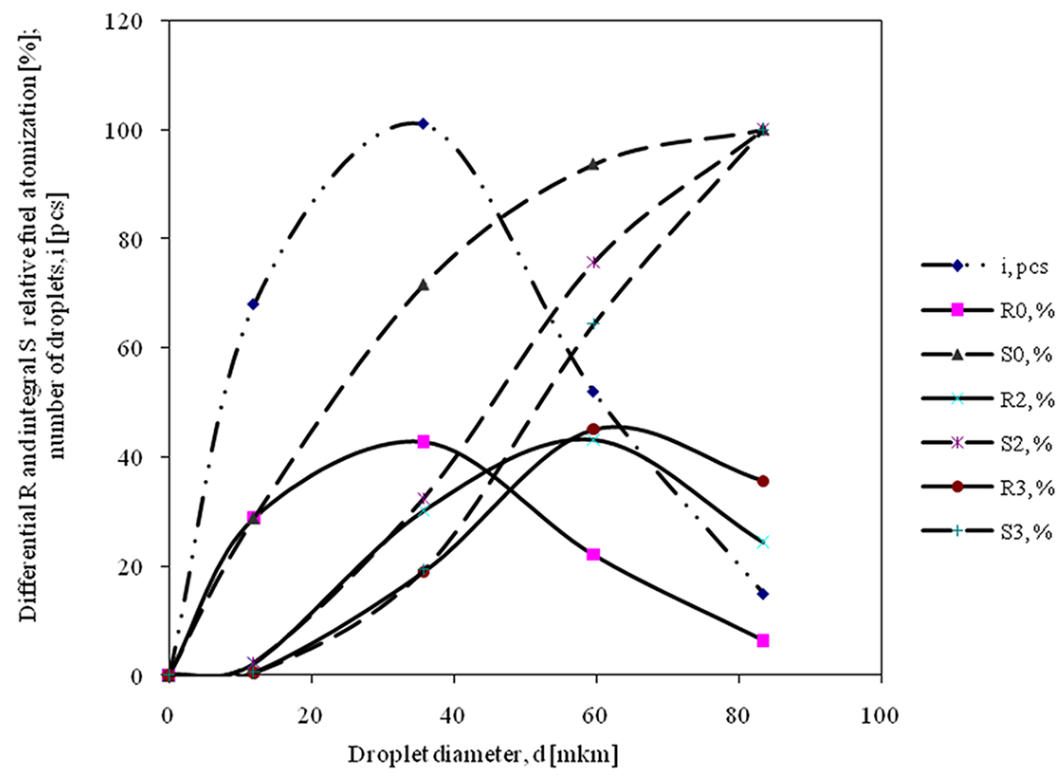

Figure 4. The relative atomization characteristics of diesel fuel (high pressure fuel pump camshaft rotation speed 900 rpm)

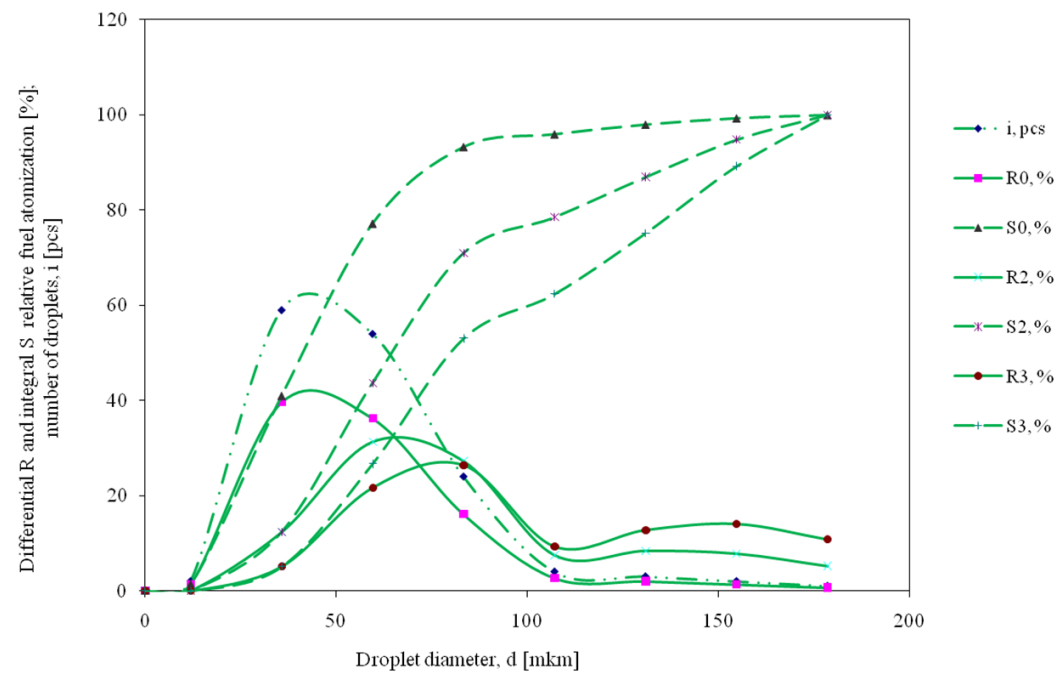

Figure 5. The relative characteristics of spray mixture DF and RO (1:1) (high pressure fuel pump camshaft rotation speed $900 \mathrm{rpm}$ ) 


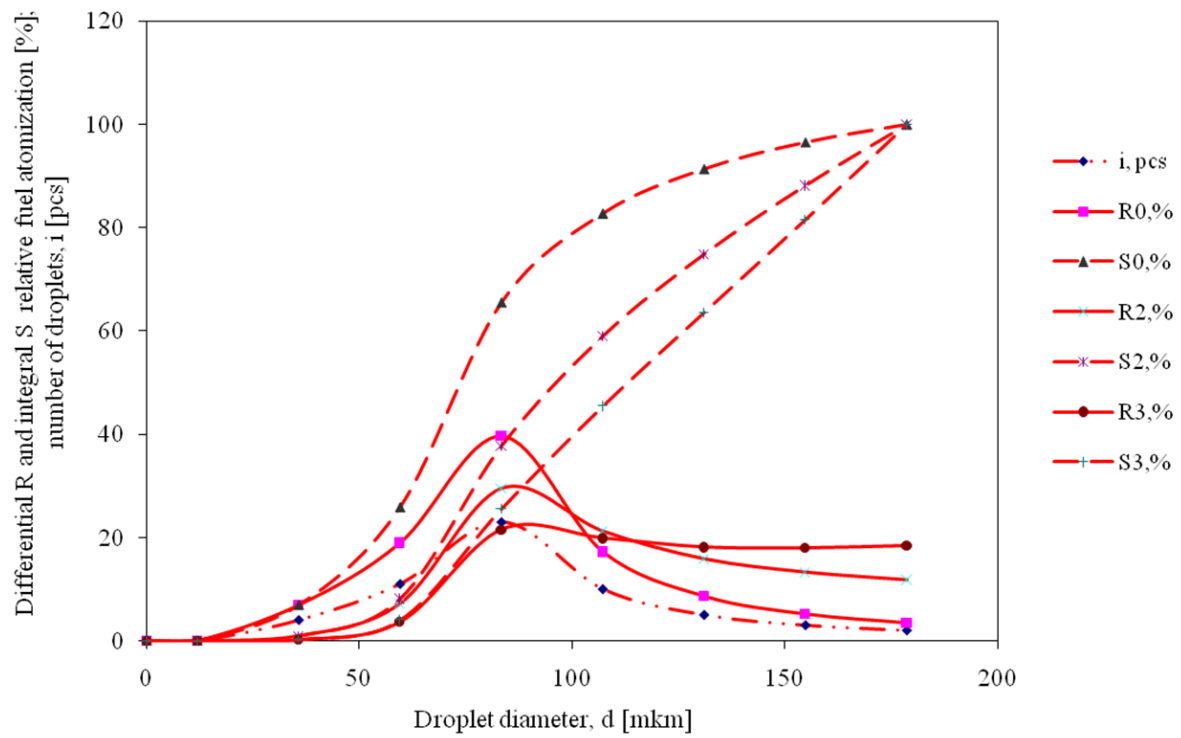

Figure 6. The relative atomization characteristics of RO (high pressure fuel pump camshaft rotation speed $900 \mathrm{rpm}$ )

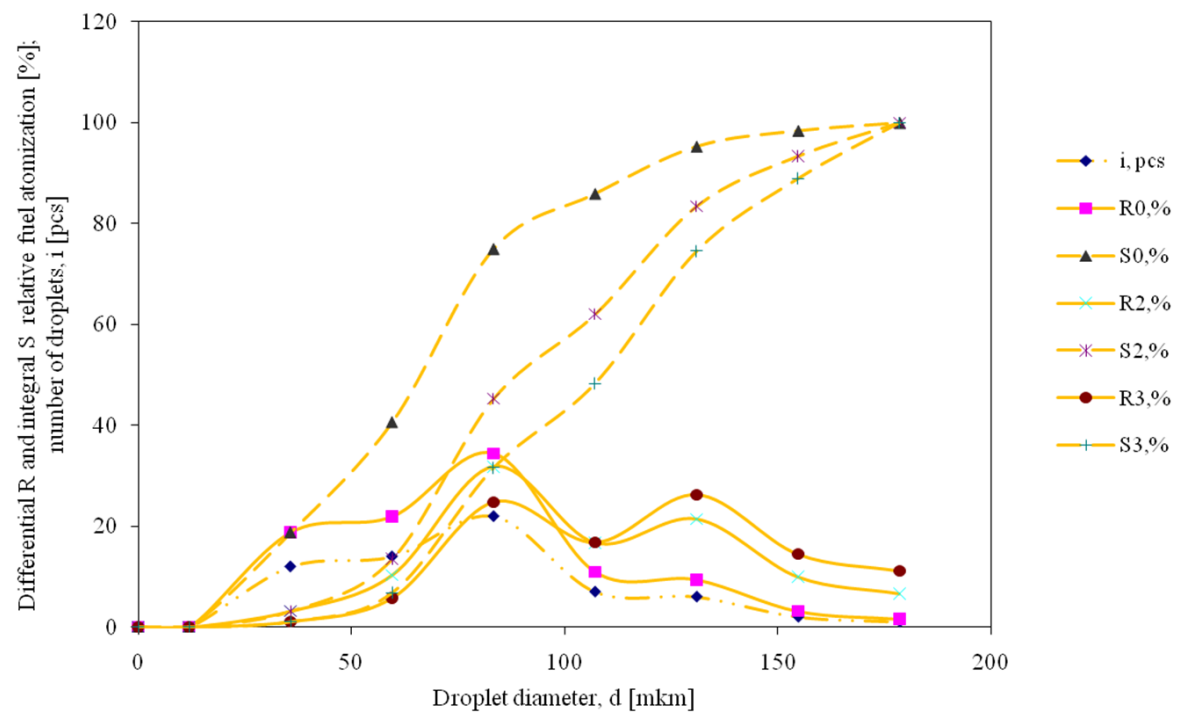

Figure 7. The relative atomization characteristics EERO (high pressure fuel pump camshaft rotation speed $900 \mathrm{rpm}$ )

Dependence (3), corrected to (4) becomes: 


$$
d_{32}=\frac{k_{f} \cdot d_{c} \cdot E_{32} \cdot M^{0.0733}}{(\rho \cdot W e)^{0.266}} .
$$

\subsection{Experimental investigations of biofuels implementation in diesel}

Experimental studies of the engine running on traditional and biofuels performed on a test bench with a diesel engine SMD-23, equipped with a turbocharged and intercooler system. Brief technical characteristics of a diesel engine SMD-23 is shown in Table. 3, the picture of experimental facility is shown in Fig. 8.

\begin{tabular}{|c|c|}
\hline Parameter & Value \\
\hline Number of cylinders & 4 \\
\hline Bore, mm & 120 \\
\hline Stroke, mm & 140 \\
\hline $\begin{array}{l}\text { The geometric compression } \\
\text { ratio }\end{array}$ & 15,5 \\
\hline Rated power, kW & 120 \\
\hline Rated speed rpm & 2000 \\
\hline
\end{tabular}

Table 3. Summary of technical characteristics of a diesel engine SMD-23

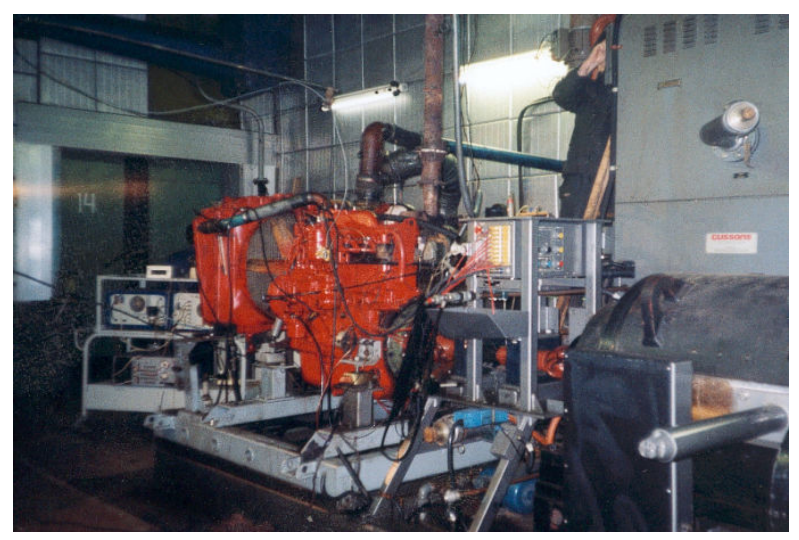

Figure 8. Experimental stand

Engine tests were conducted on the modes of engine load characteristic related to rated power mode with engine speed 2000rpm and peak torque mode with engine speed $1500 \mathrm{rpm}$. 
During the tests on each mode, the parameters of air and fuel delivery systems, exhaust gas, coolant and oil were measured. Engine speed and torque were also detected. Indexing, the definition of stroke in injector idle and measuring the pressure in the fuel injection pipe was carried out. Also emissions were measured and included $\mathrm{NO}_{2}, \mathrm{CO}$ and smoke registration.

The values of injection timing angle and adjust fuel pump adjustments remained unchanged.

Main diesel indices that running on a different fuels are shown in Fig. 9.Lets consider the effect of physicochemical properties of bio-fuels on the performance of diesel.

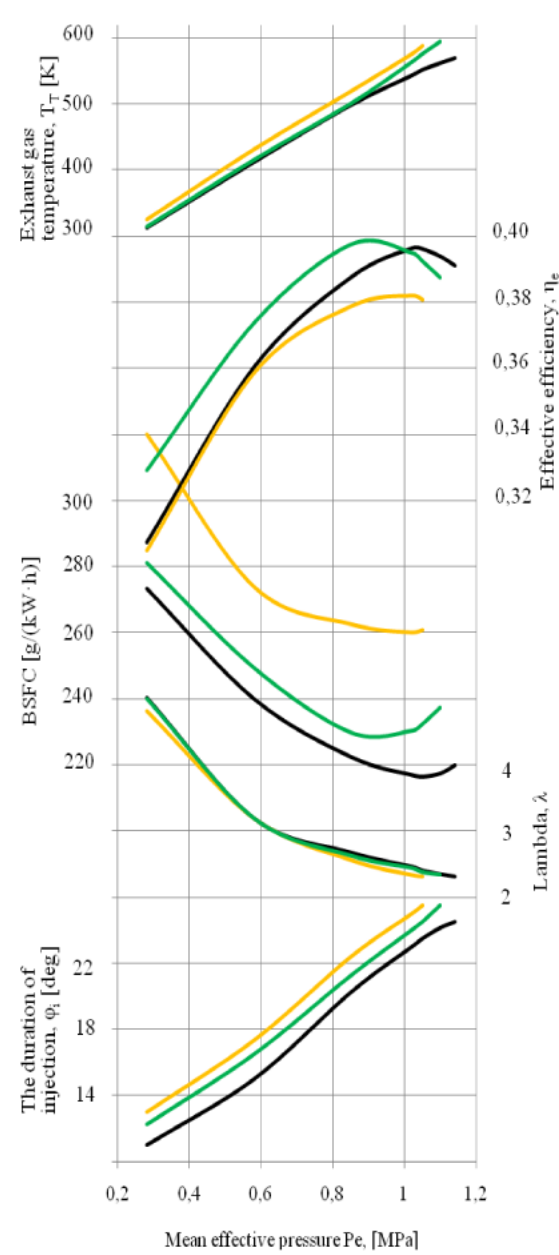

(a)

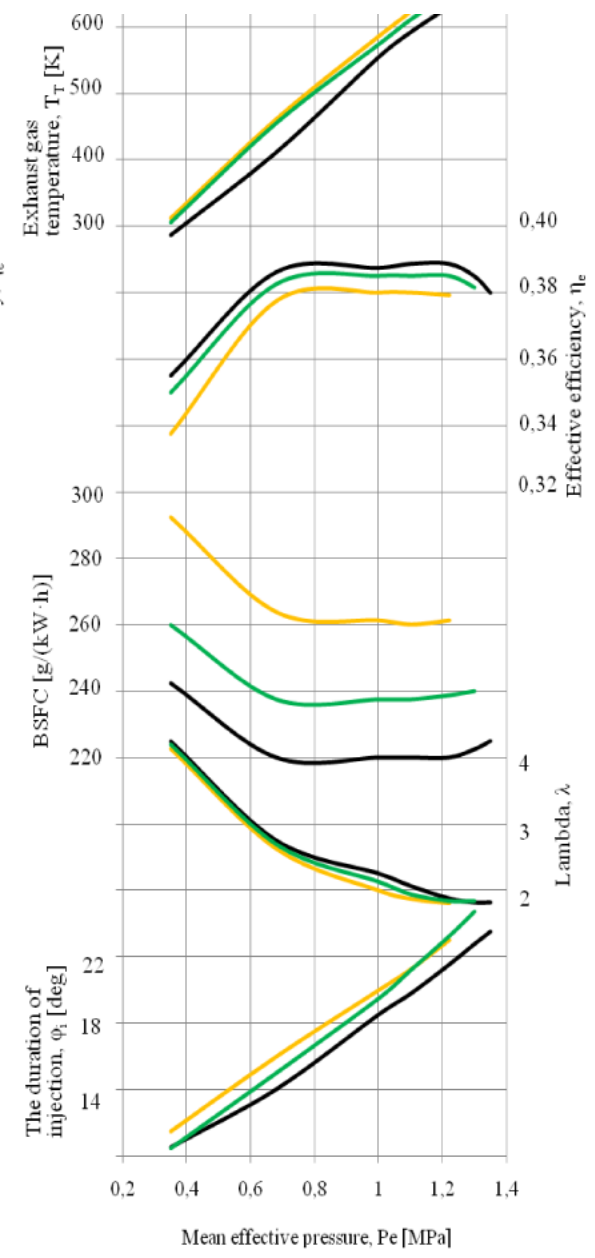

(b)

Figure 9. Effect of load on the performance of diesel exhaust gas SMD-23: engine speed $2000 \mathrm{rpm}$ (a); engine speed $1500 \mathrm{rpm}(\mathrm{b}) \_-\mathrm{DF} ;-\mathrm{EERO}$ - RO: DF (1:1) 
Injected fuel and air mixing. Injection of plant-based fuel into the combustion chamber is carried out with the higher maximum pressure than the injection of diesel fuel, which is explained by the influence of lower compressibility and higher viscosity of plant-based fuels.

Greater surface tension force and greater kinematic viscosity (see Table. 1) provide more later decay of injected plant-based fuel on the droplets and formation of smaller atomizing cone in comparison with diesel fuel. This dramatically increases the diameter of fuel droplets. As shown in [21,23,24], atomizing cone is reduced by $10 \%$ (using mthyl ester of rapeseed oil) and the average volume-surface droplet diameter d32 increases, respectively, in 1,5-1,877 times (when using pure RO, a mixture of RO and DF (1 to 1) and EERO).

Injection of plant-based fuels with the higher maximum pressures greater diameters of droplets in combination with a greater specific weight increase penetrating power and the range of fuel jet. The duration of injection of plant-based fuels $\varphi_{\mathrm{i}}$ increases slightly (1-2 crank angle) as a result of significant increase in injection pressure with a small increase in a fuel delivery.

The above factors lead to the fact that in the case of using plant-based fuels the volume fraction of mixing is reduced and the fraction of wall-film mixing is increase. The quality of volume mixing become lowered in this case.

The period of ignition delay. As a result of processing the experimental indicator diagrams, integral and differential characteristics of heat generation in the cylinder were obtained over the entire range of investigated fuel mixtures and regime characteristics of the engine. In Fig. 10 shows the relative heat generation characteristics when burned pure diesel fuel, and mixtures EERO,RO: DF (1:1) on high load $(\mathrm{Pe}=1.25 \mathrm{MPa}$ and $\mathrm{Pe}=1.01 \mathrm{MPa})$ and medium $(\mathrm{Pe}$ $=0.57 \mathrm{MPa}$ and $067 \mathrm{MPa}$ ) load at engine speed $1500 \mathrm{rpm}$ and engine speed $2000 \mathrm{rpm}$. From the analysis of these characteristics is difficult to see any legitimate differences in the ignition delay period of plant-based fuels and diesel fuel.

Consequently, we can conclude that the flammability of plant-based fuels is almost unchanged in comparison with diesel fuel flammability.

The first peak of heat generation rate. As we can see from Fig. 10, on the most modes the maximum heat generation rate for plant-based fuel in this period is lower than for diesel fuel. In addition, the area under the first peak of the curve $d x / d \varphi s m a l l e r$, and hence smaller the amount of fuel burned out in this period.

This fact is obviously related to the deterioration of the mixing between the ignition delay when using mixtures of RO with the DF and EERO. Reduction in the angle of frame divergence, increasing the relative amount of fuel that enters the wall of the combustion chamber, a significant increase in the average diameter of droplets leads to a deterioration in mixing formation and reduce the relative amount of fuel vaporized during the period of ignition delay.

The second peak of heat generation rate. After burning the fuel, evaporated during the period of ignition delay, there is a diffusion combustion of the fuel droplets in the fuel torch, as well as the fuel evaporating from the walls of the combustion chamber after the contact of the torch and the wall. The nature of the combustion process in this period determines the indicator performance of the cycle [25]. 
In an experimental engine used a cylindrical combustion chamber, that implements volumefilm mixture formation. Obtained data is contradictory ex facte (see Fig. 10). Increasing the amount of fuel reaching the wall, large diameter drops, the heterogeneity of atomization when using plant-based fuels should lead to a decrease in the rate of evaporation and combustion of fuel, especially in the modes of small loads, when the wall has a lower temperature. However, it is clear that almost on all modes there is an increase in the rate of combustion as compared to DF. The deterioration in the amount of mixing in this case does not lead to a decrease in combustion rate and it can be seen not only in the modes of high loads, but also in modes of low loads.

Intensification of the diffusion combustion of plant-basedfuels, can obviously be explained by the presence of oxygen in the structure of the molecule. When burning fuel droplets of biofuel, the oxygen is in the molecule of fuel. This oxygen is more active than molecular oxygen. That is why, even at low temperatures of plant-based fuel oxidation rate of its "own" oxygen is very high. All this probably leads to an increase in diffusion combustion rate in general.

The increase in the rate of combustion of plant-based fuels in the main period of combustion in most cases leads to a slight increase in average temperatures and pressures in the cylinder. In addition, the exhaust gas temperature rise in the exhaust manifold (see Fig. 9.).

The period of slow combustion. During this period there was burning of fuel in the cylinder. From Fig. 10 difficult to see the end of the combustion of different fuels. However, it is clear that the differences between the test fuel at the end of the combustion is low. Accelerated burning of plant-based fuels, during the second period of combustion, apparently compensate by slow combustion in the first period. So the total duration of combustion is practically unchanged.

Effective performance. As it can be seen from Fig. 9, the use of plant-based fuels leads to an increase in break specific fuel consumption because of reduction in their low heat value compared to diesel fuel. Changing in effective efficiency of the diesel engine is not so clear.

The increase in the rate of diffusion combustion, high quality film mixing on the high loads modes lead to an increase in the effective efficiency if we use plant-based fuels.

At low load modes mixture formation deteriorates in the volume of the combustion chamber. In addition, the share of plant - based fuel burning in the relatively cold wall surface areas of combustion chamber, which explains the decrease in the effective efficiency at low load modes.

The toxicity of exhaust gases. When using supplements of vegetable-based oils to diesel fuel, and if diesel engine operating on pure EERO on modes of high and medium loads the smokeemission reduced in 1.6-2 times and NO emissions increase for 5-15\%. In most modes of low-load smoke and NO are reduced (in 1.2-2 times), or remain unchanged. CO emissions using different fuels are comparable.

Experimental studies have provided initial information on the physicochemical properties of plant-based fuels, low of flow injection, atomization, mixing and combustion in the cylinder, the data for mathematical modeling processesinside the cylinder. 


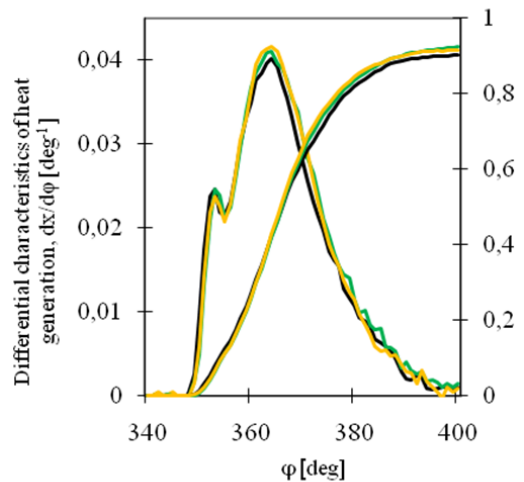

(a)

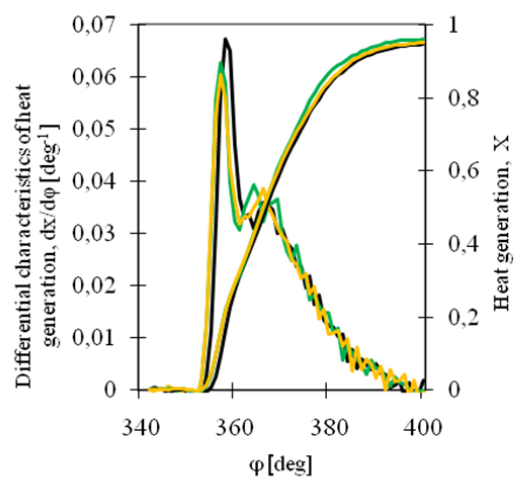

(c)

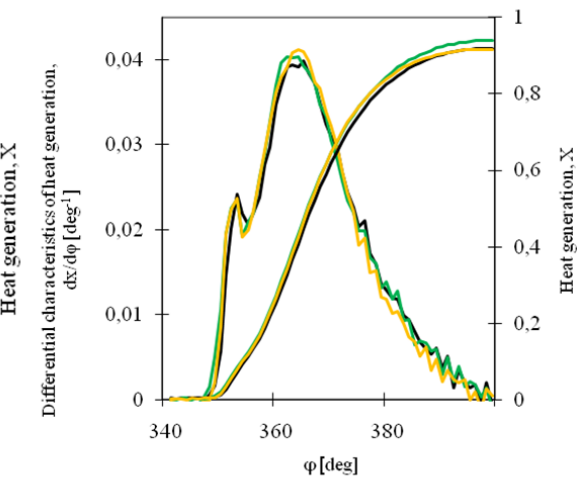

(b)

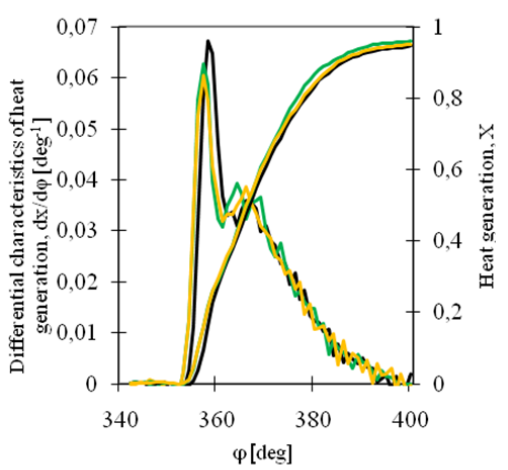

(d)

Figure 10. Heat generation characteristics in the diesel cylinder: engine speed $1500 \mathrm{rpm}: \mathrm{Pe}=1.25 \mathrm{MPa}(\mathrm{a}) \mathrm{Pe}=0.67$ $\mathrm{MPa}(\mathrm{b})$; engine speed $2000 \mathrm{rpm}: \mathrm{Pe}=1,01 \mathrm{MPa}(\mathrm{c}), \mathrm{Pe}=0,57 \mathrm{MPa}(\mathrm{d})$; $-\mathrm{DF}$; - EERO; R RO: DF (1:1)

These differences in the physicochemical properties of biofuels and their impact on flow processes in the cylinder of a diesel engine form the basis for the developed mathematical model of combustion.

\section{Description of the proposed mathematical model of combustion}

Lets consider the features of the proposed model of combustion. 
Differential characteristic of heat generation proposed to describe by two curves corresponding to the periods of ignition (or "fast" combustion) and the diffusion combustion

$$
\begin{gathered}
\left(\frac{d x}{d \varphi}\right)_{I}=-A \cdot C \cdot \exp \left(C \cdot \bar{\varphi}_{I}^{m_{I}+1}\right) \frac{6 n}{\varphi_{z I}}\left[\left(m_{I}+1\right) \bar{\varphi}_{I}^{m_{I}}+\bar{\varphi}_{I}^{m_{I}+1} \ln \overline{\varphi_{I}} \frac{d m_{I}}{d \overline{\varphi_{I}}}\right] \\
\left(\frac{d x}{d \varphi}\right)_{I I}=-C \cdot \xi_{v} \cdot S \cdot \exp \left(C{\overline{\varphi_{I I}}}^{m_{I I}+1}\right) \frac{6 n}{\varphi_{z_{I I}}}\left[\left(m_{I I}+1\right) \bar{\varphi}_{I I}^{m_{I I}}+\bar{\varphi}_{I I}^{m_{I I}+1} \ln \overline{\varphi_{I I}} \frac{d m_{I I}}{d \overline{\varphi_{I I}}}\right]
\end{gathered}
$$

where $A$ - coefficient taking into account the influence of the proportion of vaporized fuel during the ignition delay at the rate of fast combustion;

C - coefficient taking into account the completeness of combustion;

$\xi \mathrm{v}$ - the degree of efficient use of air charge;

$S$ - coefficient taking into account the share of fuel burned for the period of the ignition (linking the two periods).

The index «I» related to parameters that identified ignition, the index «II» - the process of diffusion combustion.

Dynamics indicators for the respective periods of combustion:

$$
\begin{aligned}
& m_{I}=4 \cdot \bar{\varphi}_{m I} \cdot\left(1-\bar{\varphi}^{-\bar{\varphi}_{m I}}\right) \\
& m_{I I}=9 \cdot \bar{\varphi}_{m I I} \cdot\left(1-\bar{\varphi}^{-\bar{\varphi}_{m I I}}\right)
\end{aligned}
$$

where $-\bar{\varphi}_{m I}$ and $\bar{\varphi}_{m I I}$ relative moments of maximum heat generate rate;

$\bar{\varphi}_{I}$ and $\bar{\varphi}_{I I}$ - the relative angles of the crankshaftrotation: $\bar{\varphi}_{I}=\varphi / \varphi_{Z I}, \bar{\varphi}_{I I}=\varphi / \varphi_{Z I I} ;$

$\varphi$ - the current angle of the crankshaft rotation from the start of combustion;

$\varphi_{\mathrm{ZI}} \varphi_{\mathrm{ZII}}$ - respectively, the duration of fast and diffusive combustion.

At each calculated section the values $\left(\frac{d x}{d \varphi}\right)_{I}$ and $\left(\frac{d x}{d \varphi}\right)_{I I}$ was comparing. The final calculated heat generation rate $\frac{d x}{d \varphi}$ took the value of greater meaning of two rates.

The total amount of burnt fuel are determined by integrating the function $d x / d \varphi$ in the area of combustion 


$$
x=\int_{\varphi_{N}}^{\varphi_{k}} \frac{d x}{d \varphi} d \varphi,
$$

where $\varphi_{\mathrm{N}}, \varphi_{\mathrm{k}}$ - respectively the beginning and the end of combustion.

In formulas (6) - (9) there are the parameters $A$ and, $\varphi_{\mathrm{ZI}}$ and $\varphi_{\mathrm{ZII}}, \xi_{\mathrm{V}}$, which, unlike the parameters of the known formulas Vibe I.I. accounted specific processes of fuel injection, mixing, evaporation, combustion, and the interaction of these processes with each other.

In generalizing the data obtained by processing the experimental indicator diagrams, empirical correlations was proposed to determine the relative moment of maximum heat generation rate during periods of combustion:

$$
\bar{\varphi}_{m I}=0,8+\frac{0.03 \cdot b_{\grave{e}} \cdot \varphi_{\mathrm{ZI}}}{6 \cdot n} ; \bar{\varphi}_{m I I}=0,16+\frac{0.03 \cdot b_{\grave{e}} \cdot \varphi_{\mathrm{ZII}}}{6 \cdot n}
$$

where $b_{u}$ - a constant of relative evaporation.

The relative constant of evaporation

$$
b_{u}=K_{u} / d_{32}^{2}
$$

where $K_{u}$ - constant of evaporation, calculated for the average diameter $d_{32}$ of the droplet under Sauter.

Prof. Razleytsev [8] estimated, that during the evaporation of fuel in a diesel engine cylinder the average evaporation constant:

$$
K_{u T}=\left(10^{6} p_{c}\right)^{-1}
$$

where $p_{c}$-the pressure in the cylinder at the end of a conditional extension to TDC compression. Theoretical constant $K_{u T}$ does not include an increase in the rate of evaporation of droplets during combustion, the effect of size of drops, speed and frequency of turbulent vortices arising in the diesel cylinder. This dependence is in practical calculations can be taken into account by correction function $\Upsilon$ :

$$
K u=Y \cdot K_{u T}
$$

In [8] proposed the following formula for determining the correction function: 


$$
Y=y\left(W_{T} d_{32}\right)^{0.75} p_{C}^{0.25}
$$

where $y$ - constant empirical coefficient depending on the design of the combustion chamber and taking into account the effect of unaccounted secondary factors.

$W_{T}$ - the tangential velocity of the charge in the combustion chamber;

$p_{c}$ - the calculated pressure at the end of a conditional extension to TDC compression.

It should pay particular attention to the coefficient of $y$. It is obvious that there are permanent factors that defined $y$ coefficient - engine design, adjustments and settings mode. On the other hand, while using different fuels - the value of this ratio will be determined by physical and chemical properties of fuels.

As shown in Section 2, an important property of plant-based fuelsthat have a material effect on the combustion process is the oxygen content in the molecule. Increasing the number of bound oxygen in the molecule leads to an increase in the rate of diffusion combustion. Accordingly, the simulation of combustion is expedient to increase the coefficient $y$ proportional to the share of the oxygen in the molecule of fuel.

In this study, a constant value $y$ was adjusted for each fuel type on the basis of providing the best agreement between calculated and experimental data. For all the calculations for one type of fuel $y$ constant has not changed.

In accordance with the original model [19] the duration of diffusion combustion:

$$
\tau_{z I I}=\varphi_{i}+\varphi_{b}
$$

where $\varphi_{i}$ - the duration of fuel injection;

$\varphi_{b}$ - the duration of burn-out fuel after the injection.

The duration of burn-out fuel $\phi_{b}$ characterized by the time of evaporation and combustion of large droplets delivered in the diesel engine cylinder at the end of injection. This time depends on the fineness of atomization, the distribution of drops, the parameters of the working fluid in the cylinder, air-fuel ratio, etc. $\phi_{b}$ can be calculatedfrom the formula [8]:

$$
\varphi_{b}=K_{\alpha} \cdot \varphi_{e^{\prime}}
$$

where $\phi_{e}$ - the duration of the evaporation of large droplets of fuel;

$K_{\alpha}$ - correction function which takes into account the time of fuel vapors burning.

The duration the large droplets evaporation of fuel: 


$$
\varphi_{e}=\frac{d_{K}^{2}}{K_{u}}
$$

where $d_{K}$ - an average diameter of large drops of fuel injected into cylinder by the end of the fuel delivery.

In [8] proposed to determine the diameter of the large drops by the formula:

$$
d_{K}=B \cdot d_{32}
$$

In this formula, the size factor is:

$$
B=1.5+0.018 \exp \left(\Delta p_{f_{i}}^{0.272}\right)
$$

where $\Delta p_{f i}$ - the average pressure drop during injection, MPa.

Correction function at the time of burning-out of fuel vapors can be determined from the dependence [8] :

$$
K_{\lambda}=1+A_{3} K_{u} /(\lambda-1)
$$

where $\lambda$ - is the ratio of actual air-to-fuel ratio to stoichiometry for a given mixture;

$A_{3}$ - coefficient, which is determined by identifying a number of experimental data for defined row of engines and can be taken equal to $2.5 \bullet 10^{6}$.

We proposed to determine the duration of the fast combustion as a function of the duration of the ignition delay period:

$$
\tau_{z I}=\tau_{i} \cdot K_{\lambda^{\prime}}
$$

where $\tau_{i}$ - the period of ignition delay in seconds.

If to go to the crank angle, the duration of fast and diffusive combustion are determined by the following formulas: 


$$
\varphi_{\mathrm{ZI}}=\tau_{\mathrm{ZI}} 6 n ; \varphi_{\mathrm{ZII}}=\theta_{i}+\varphi_{b} 6 n
$$

where $\theta_{i}$ - injection advanced angle.

In developed model has been assumed that burn rate during the ignition mostly depends on the amount of fuel vaporized during the period of ignition delay. In turn, the calculation of the first peak heat generation rate coefficient taking into account the influence of the proportion of vaporized fuel during the ignition delay period.

$$
A=K_{I} \cdot \sigma_{I}
$$

where $\sigma_{\mathrm{I}}$ - the relative amount of fuel injected during ignition delay period $\varphi_{\mathrm{I}}$;

$\mathrm{K}_{\mathrm{I}}$ - coefficient of proportionality.

In [23] proposed the dynamics of heat generation during diffusion combustion (equation (7)) to adjust with the ratio $\xi \mathrm{v}$, which is a degree of efficient use of air charge in cylinder:

$$
\xi_{V}=\frac{\lambda_{\grave{o}}}{\lambda}
$$

where $\lambda_{\mathrm{m}}$ - the average $\lambda$ coefficient in the combustion zone;

$\lambda$ - the estimated value of $\lambda$ in the cylinder for full combustion of the fuel injected into the cylinder.

The coefficient $\xi_{V}$ takes into account the interaction of fuel torch with the wall of the combustion chamber and other factors that reduce the amount of oxidant entering the combustion zone. In $[23,28]$ describes a method of determining this ratio.

The mathematical model of combustion is integrated into the thermodynamic model of the closed-loop workflow engine with a turbocharger.

\section{Implementation of mathematical models for practical calculations}

Comparison of calculated and experimental characteristics of heat generation and indicator diagrams using different fuels is shown in Fig. 11-13. It can be seen that the proposed mathematical model provides a satisfactory agreement between the calculated and experimental data in a wide range of biofuels, loads and engine speeds.

A precise description of the combustion process is important in modeling the formation of harmful substances in the cylinder. For example, the error in determining the temperature in 
the cylinder $80-90 \mathrm{~K}$ leads to a change in the calculated NO output by $30 \%$, error in determining the temperature of $190 \mathrm{~K}$ change in the calculated NO output is 2.7 times [26]. Obviously, using the proposed mathematical model rather than empirical or semi empirical models provide a more accurate calculation of the formation of harmful substances in the diesel engine cylinder.

The adequacy of the developed mathematical model was tested also for its response to the changing influence of parameters - the compression ratio, injection duration and injection delay angle (Fig. 14). It is seen that the obtained numerical data trends and logical and do not conflict with similar data of other researchers [26-28].

We can conclude that the developed mathematical model allows us not only to describe the dynamics of heatgeneration with sufficient accuracy, but also to adequately respond to changes in design and adjustments in the parameters of diesel.

\section{Conclusion}

Actual and perspective task for modern engine - building has been introduced and solved in the chapter. This task included the development of mathematical model of alternative (biofuels) and fossil fuel (diesel) combustion calculation in the cylinder of diesel engine. It is shown that the physical-chemical properties of biofuels differ significantly from the properties of diesel fuel, which leads to changes in the processes of fuel injection, mixture formation and combustion. All this has a significant impact on the efficient and environmental performance of diesel engines.

Authors have proposed mathematical model that adequately describes the process of combustion of conventional diesel and bio-fuel in the cylinder of diesel engine. It was confirmed by the results of calculation and experimental studies.

The mathematical model proposed by the authors can be used to solve optimization tasks in internal combustion engines running on a diesel fuel, as in this model combustion processes are linked with parameters of engine design and engine working process parameters. The model is developed in a parametric form and reflects the change in design and adjustment parameters of the diesel engine.

An important characteristic of a new mathematical model is an adequate description of the first phase of the combustion process (first peak), which is associated with fuel burn-out, accumulated during the ignition delay, which allows more reliable to calculate the temperature of the working fluid in the cylinder of diesel engine and, consequently, with greater reliability to calculate by Zeldovich methoda number of nitrogen oxides that are formed in the cylinder of diesel engines.

The proposed model can be used in university training programs for professionals in the field of internal combustion engines, as well as in practice of firms participating in the modernization of existing and development of advanced diesel engines. 

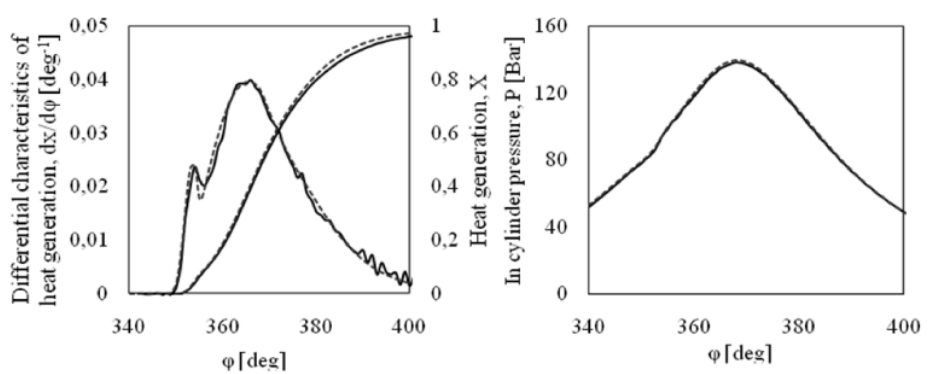

(a)
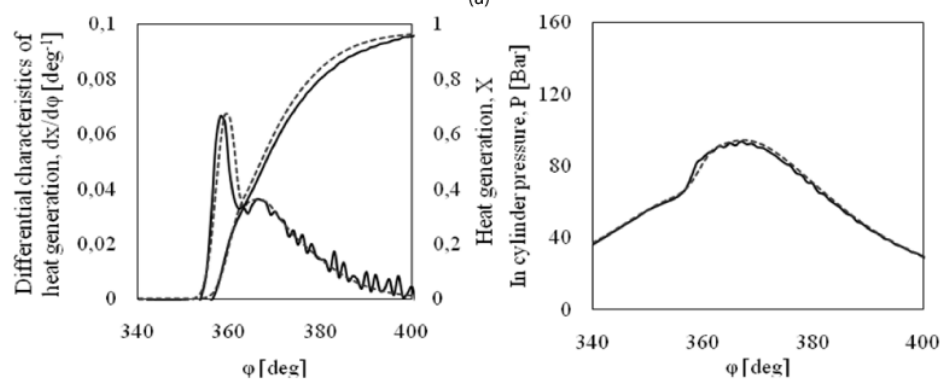

(b)
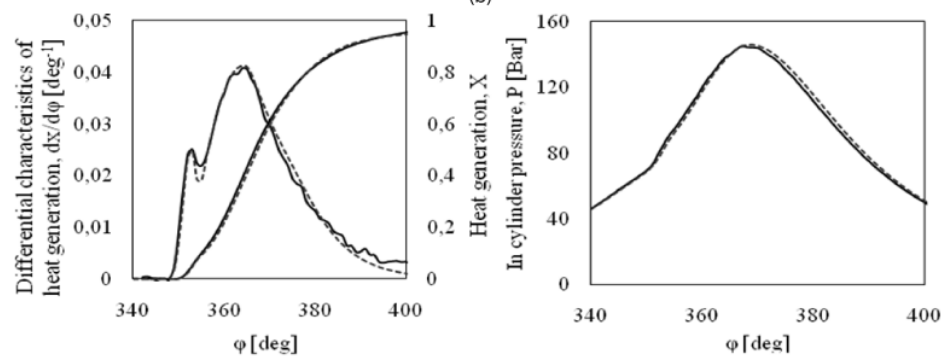

(c)
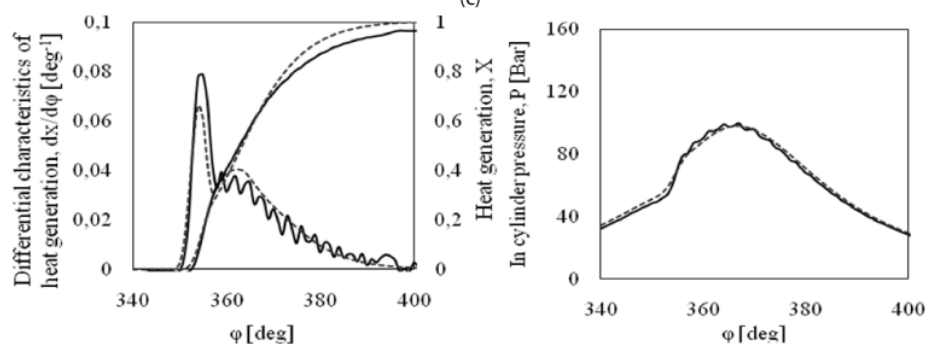

(d)

Figure 11. Verification of the model of calculation of heat generation process. Diesel: engine speed $2000 \mathrm{rpm}, \mathrm{Pe}=1.1$ $\mathrm{MPa}(\mathrm{a})$; engine speed $2000 \mathrm{rpm}, \mathrm{Pe}=0.56 \mathrm{MPa}$ (b); engine speed $1500 \mathrm{rpm}, \mathrm{Pe}=1.35 \mathrm{MPa}$ (c); engine speed 1500 rpm,pe=0.67 MPa (d); Experiment; 

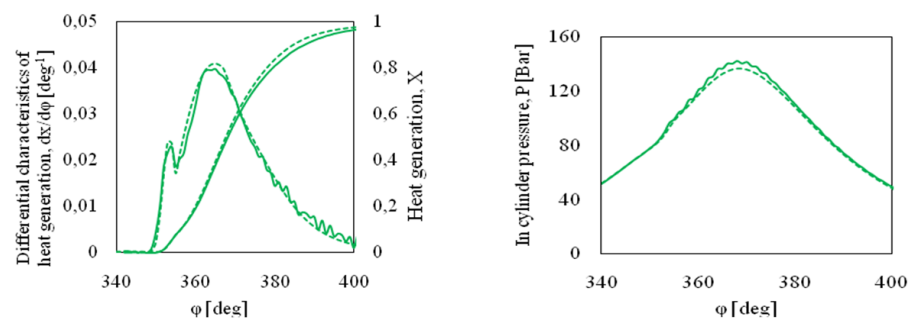

(a)
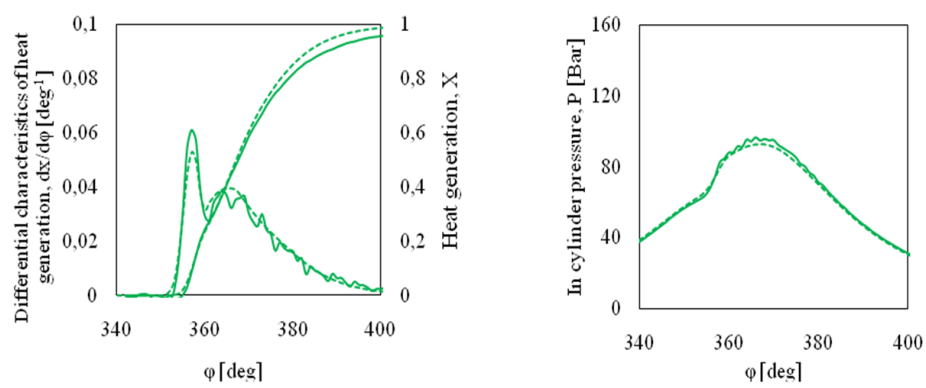

(b)
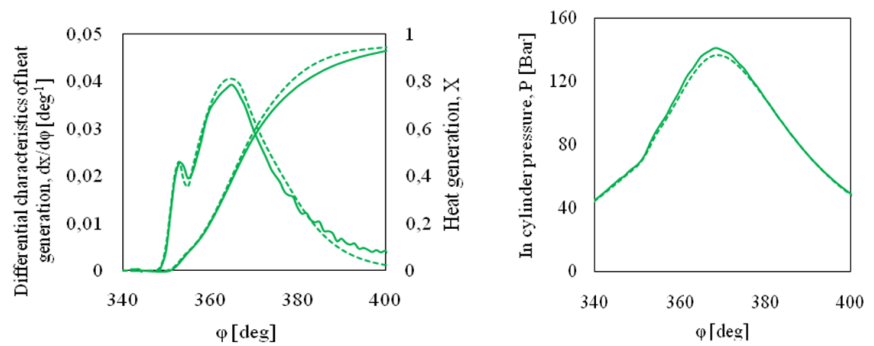

(c)
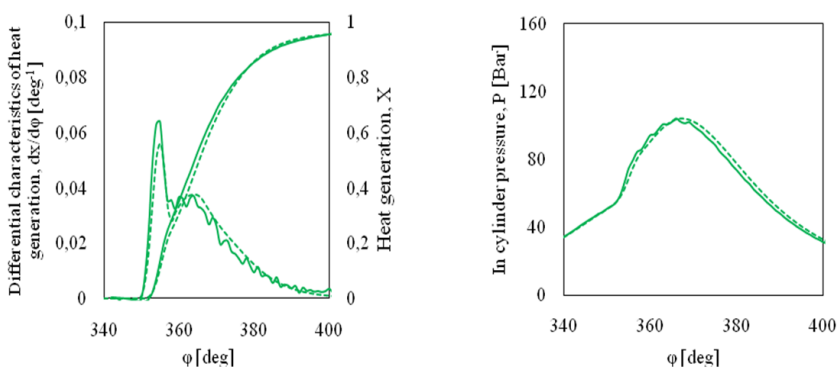

(d)

Figure 12. Verification of the model of calculation of heat generation process. A mixture of RO: DF (1:1): engine speed $2000 \mathrm{rpm}, \mathrm{p}_{\mathrm{e}}=1.1 \mathrm{MPa}(\mathrm{a})$; engine speed $2000 \mathrm{rpm}, \mathrm{p}_{\mathrm{e}}=0.56 \mathrm{MPa}$ (b); engine speed $1500 \mathrm{rpm}, \mathrm{p}_{\mathrm{e}}=1.35 \mathrm{MPa}$ (c); engine speed $1500 \mathrm{rpm}, \mathrm{p}_{\mathrm{e}}=0.67 \mathrm{MPa}(\mathrm{d})$; Experiment; 

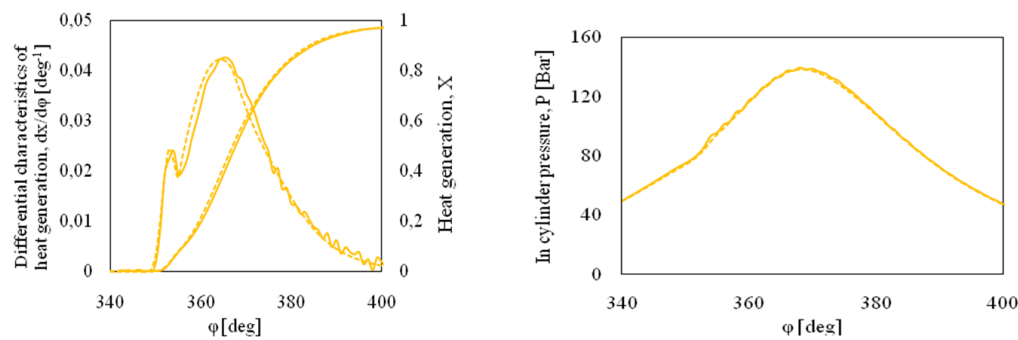

(a)
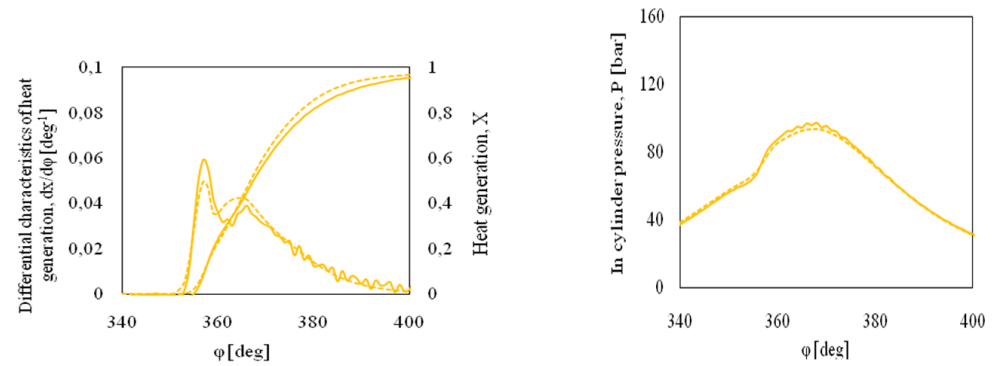

(b)
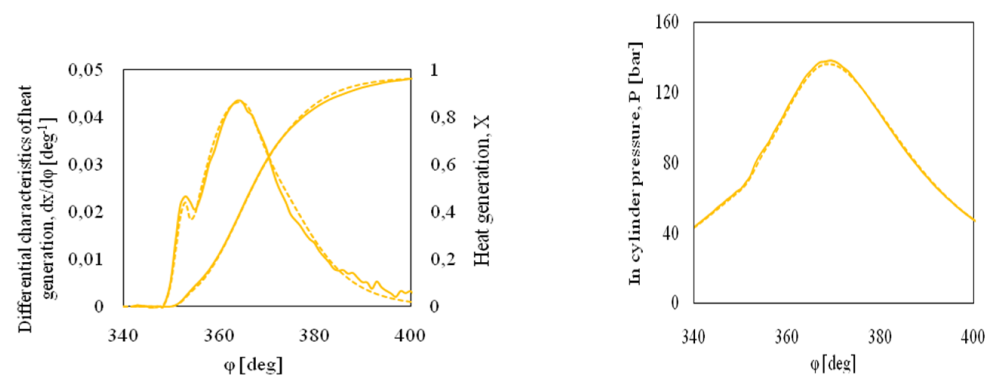

(c)
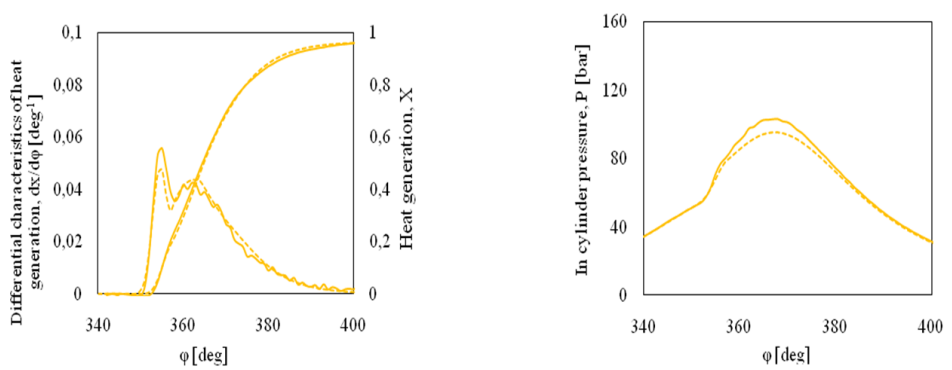

(d)

Figure 13. Verification of the model of calculation of heat generation process. EERO: engine speed $2000 \mathrm{rpm}, \mathrm{p}_{\mathrm{e}}=1.1$ $\mathrm{MPa}(\mathrm{a})$; engine speed $2000 \mathrm{rpm}, \mathrm{p}_{\mathrm{e}}=0.56 \mathrm{MPa}$ (b);engine speed $1500 \mathrm{rpm}, \mathrm{p}_{\mathrm{e}}=1.35 \mathrm{MPa}$ (c); engine speed $1500 \mathrm{rpm}$, $\mathrm{p}_{\mathrm{e}}=0.67 \mathrm{MPa}(\mathrm{d})$; Experiment; $-\ldots-\ldots-$ Calculation of the refined model 


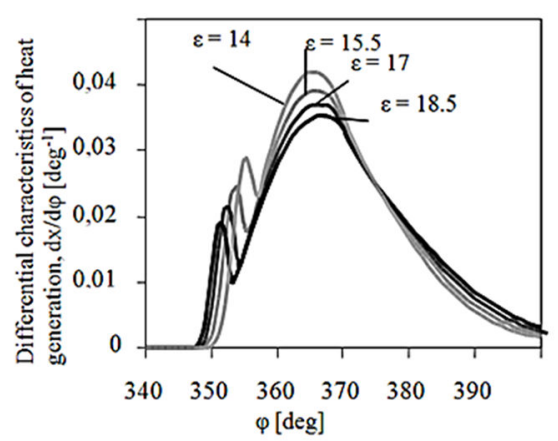

(a)

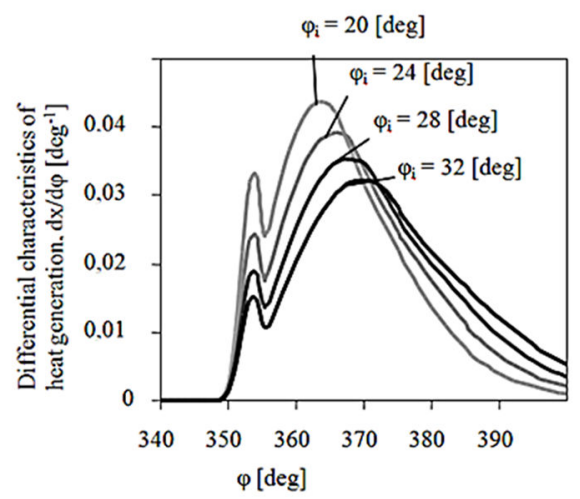

(c)

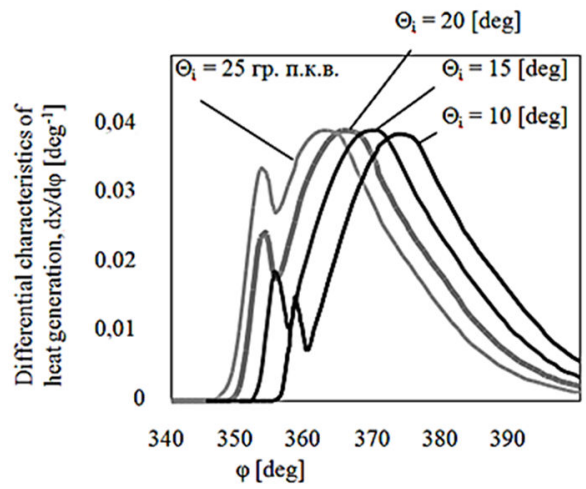

(e)

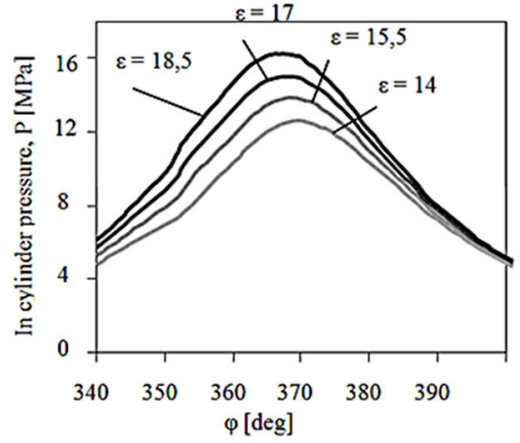

(b)

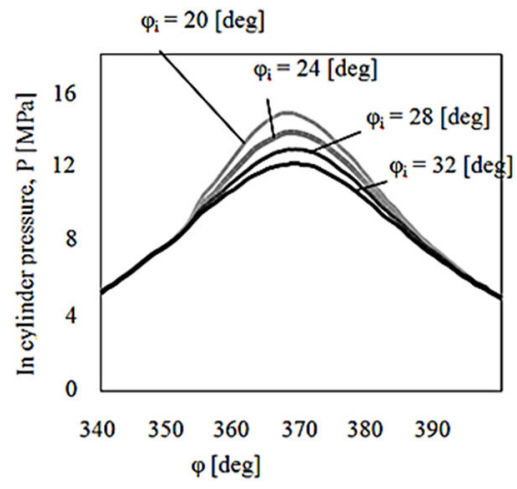

(d)

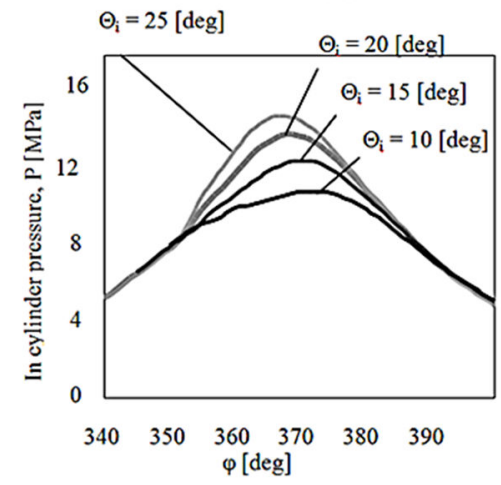

(f)

Figure 14. Effect of changing the compression ratio $\varepsilon(a, b)$, the injection duration $\varphi_{i}(c, d)$ and injection delay angle $\Theta_{i}$ $(e, f)$ at the rate of heat generation and pressure in the cylinder of diesel engine 


\section{Author details}

Andrey Marchenko, Alexandr Osetrov, Oleg Linkov and Dmitry Samoilenko

National Technical University "Kharkiv Polytechnic Institute", Ukraine

\section{References}

[1] Priesching, P., Ramusch, G., Ruetz, J. and Tatschl, R., 3D-CFD Modeling of conventional and Alternative Diesel Combustion and Pollutant Formation - A Validation Study. SAE 2007-01-1907 2007.

[2] Tatschl, R., Priesching, P., Ruetz, J. and Kammerdiener, Th., DoE Based CFD Analysis of Diesel Combustion and Pollutant Formation. SAE 2007-24-0048 2007.

[3] Dahlen, L. and Larsson, A., CFD Studies of Combustion and In-Cylinder Soot Trends in a DI Diesel Engine - Comparison to Direct Photography Studies. SAE 2000-01-1889 2000 .

[4] Kong, S.-C., Han, Z.Y. and Reitz, RD, The Development and Application of a Diesel Ignition and Combustion Model for Multidimensional Engine Simulations. SAE 9502781995.

[5] Kolade B., Thomas M., Kong SC, "Coupled 1D/3D analysis of fuel injection and diesel engine combustion", SAE International, vol.1, 1102004.

[6] FIRE v2009 Manual. AVL List GmbH, Graz 2009.

[7] Razleytsev N.F. Modelling and optimization of the combustion process in diesel engines. - Kharkov: Kharkov university press.; 1980.

[8] Kuleshov A.S. The program for calculating and optimizing the internal combustion engine DIESEL-RK. Description of mathematical models, solving optimization problems. M. Bauman. Bauman; 2004.

[9] Hiroyuki Hiroyasu, Toshikazu Kadota and Masataka Arai. Development and Use of a Spray Combustion Modeling to Predict Diesel Engine Efficiency and Pollutant Emissions. JSME1983; 26(214) 576-583.

[10] Wiebe I.I.New about working cicle of engines. Moscow - Sverdlovsk: Mashgiz; 1962.

[11] Watson, N., Pilley, A.D., Marzouk, M. A Combustion Correlation for Diesel Engine Simulation. Diesel Combustion and Emissions. SAE Society of Automotive Engineers 1980; 86 51-63.

[12] Gonchar V.M. Numerical simulation of the working cicle in Diesel. Power machine building; $734-35$. 
[13] Ramos JI. Internal Combustion Engine Modeling. Hemisphere Publishing Corporation; 1989.

[14] Blumberg P., Kummer I.T. Prediction of NO Formation in Spark-Ignited Engines An Analisys of Methods of Control.Combustion and Flame 1975; 2515-23.

[15] Lino Guzzella and Christopher H. Onder. Introduction to Modeling and Control of IC Engine Systems. Springer; 2007.

[16] ZeldovichY.B., GardenersP.Y., Frank-KamenetskyD.A. Oxidation of nitrogen during combustion. Moscow - Leningrad: AN USSR; 1947.

[17] Semenov V.S. Current problems of the theory of marine diesels. M.: I / O : Mortehinformreklama; 1991.

[18] Varbanets R. The parametric diagnostics of diesel engines SBV6M540 and Pegaso 9156 / R. Varbanets. Aerospace technic and technology 2006; 8 (34) 144-148.

[19] FilipkovskyA.I. Improvement of working process in diesel tipe 32/32 on the basis of physical and mathematical simulation.PhDthesis. HIIT; 1988.

[20] Taldy G.B., Krivobokov A. Numerical Simulation of the combustion process in diesel. Aerospace Engineering and Technology2000; 19158.

[21] LotkoB., LukaninV., Khachiyan, A. Theuseofalternativefuelsininternalcombustionengines. Moscow: MADI (TU); 2000.

[22] Lyshevsky.Theprocessesofatomizationofdieselfuelinjectors. Moskow: Mashgiz; 1963.

[23] Linkov O. Selection and validation of the parameters of mixture formation and combustion of diesel engine operating on alternative fuels. PhDthesis. NTU "KPI"; 2004

[24] MarchenkoA., SemenovV., Sukachev I.I., Linkov O. Simulation of features of the working process in SMD-31 diesel engine running on traditional diesel fuel and methyl esters of rapeseed oil. Aerospace Engineering and Technology2000; 19155-157.

[25] The theory of internal combustion enginesEd. DyachenkoN.H. L.: Mechanical Engineering; 1974. - $552 \mathrm{p}$.

[26] Zvonov V.A. The toxicity of internal combustion engines. -M.: Mechanical Engineering, 1981.

[27] MarkovV., KislovV., Khvatov V.A. Characteristics of fuel delivery in diesel engines. Moscow: Publishing House of the MSTUBauman; 1997.

[28] ParsadanovI.V. Improving the quality and competitiveness of diesel engines through an integrated fuel efficiency and environmental criteria: the monograph . Kharkov: NTU "KPI"; 2003. 
